\title{
Applicability of Paediatric Index of Mortality 2 Score to Predict Outcome in Children Admitted to Paediatric Intensive Care Unit
}

\author{
Aroor S', Kumar S', Kini $\mathbf{P}^{3}$, Mundkur $\mathbf{S}^{4}$
}

\section{Abstract}

Introduction: Research on critically ill children admitted to the intensive care unit has shown the usefulness of Paediatric Index of Mortality 2 (PIM2) score at admission to predict outcome. This study was conducted to estimate PIM2 score in children admitted to Paediatric Intensive Care Unit and its correlation with clinical outcome.

Material and Methods: This prospective observational study was conducted in children of age group one month to 18 years admitted to the paediatric intensive care unit of a tertiary care hospital. Data including demographics, diagnostic categories, duration of hospital stay, predicted death rate (PDR) measured by PIM2 score was compared between survivors and non survivors. Logistic regression analysis was performed to arrive at a risk adjusted relationship between the different predictor variables and the probability of death.

Results: Consecutive 130 children admitted to PICU during the study period were enrolled. The mean PDR (\%) of the total study population was $22.4 \pm 10.60$. The mean PDR in survivors was $12.4 \pm 7.80$ while the PDR in non survivors was $44.2 \pm 12.62$ ( $p$ value $<0.001)$. Children with PDR $<1 \%$ had a mortality rate of $2.4 \%$ when compared to $71.4 \%$ in children with PDR $>5 \%$ ( $p$ value $<0.001$ ). PDR by PIM2 score and the presence of hypo-albuminemia remained significant even after adjusting for age in multivariate logistic regression analysis. Conclusion: PDR measured by PIM2 score differentiated well between survivors and non survivors in PICU. The predicted death rate was less than the observed death rate. PIM2 score is a useful tool to assess the severity of illness and predict outcome.

Key words: critically ill; mechanical ventilation; PIM2 score; predicted death rate

\section{Introduction}

everal severity scoring systems are validated to predict morbidity and mortality in children admitted to Paediatric Intensive Care Unit (PICU). Though traditionally scoring systems were used to predict prognosis of patients, in addition they have been used as performance indicators of critical care units. ${ }^{1}$ In these scoring systems
${ }^{1}$ Dr. Shrikiran Aroor, Professor; ${ }^{2} \mathrm{Dr}$. Sandeep Kumar, Associate Professor; ${ }^{3} \mathrm{Dr}$. Pushpa Kini, Professor; ${ }^{4} \mathrm{Dr}$. Suneel Mundkur, Associate Professor. All from the Department of Paediatrics, Kasturba Medical College, Manipal Academy of Higher Education, Manipal, India.

\author{
Address for correspondence \\ Dr. Sandeep Kumar \\ Associate Professor, \\ Department of Paediatrics, \\ Kasturba Medical College, \\ Manipal Academy of Higher Education, \\ Manipal, Karnataka, India \\ E-mail: bksandydoc@gmail.com
}

\author{
Acknowledgements: None \\ Funding: Nil \\ Conflict of Interest: None \\ Permission from IRB: Not Submitted
}

How to cite

Aroor S, Kumar S, Kini P, Mundkur S. Applicability of Paediatric Index Mortality of 2 Score to Predict Outcome in Children Admitted to Paediatric Intensive Care Unit. J Nepal Paediatr Soc 2018;38(3):149-52.

doi: http://dx.doi.org/10.3126/jnps.v38i3.23146

Submitted on: 2019-03-16

Accepted on: 2020-02-12

This work is licensed under a Creative Commons Attribution 3.0 License.

\section{(c) (i)}


the relationship between the predictor variables and the probability of death is estimated using logistic regression models. $^{2}$

Though many scoring systems are available, few of them which are validated in paediatric age group include some Paediatric Risk of Mortality (PRISM) III, Paediatric Multiple Organ Dysfunction (PEMOD) scoring system, Paediatric Logistic Organ Dysfunction (PELOD) scoring system and Paediatric Index of Mortality (PIM) scoring system. Paediatric Index of Mortality (PIM) score was first designed by Shann et al. in 1997 which was later updated in 2003 to PIM-2 that has better predictability in assessing the outcome. ${ }^{3}$

Several studies done in developed as well as developing countries have shown PIM2 score as a better performance indicator and predictor of mortality. ${ }^{4-6}$ Though PIM2 score is easy to calculate and has good ability to discriminate between survivors and nonsurvivors, studies have shown a difference in the predicted mortality and the observed mortality. The validation of PIM2 scoring system is best performed in a large cohort population and not in a single PICU setting. Hence this study was performed to estimate whether PIM 2 score is useful in predicting outcome of children and its ability to discriminate between survivors and non-survivors.

\section{Material and Methods}

This was a cross sectional observational study conducted at the PICU of the department of Paediatrics, in a tertiary level care teaching institute in Southern India. The study was conducted over a period of 4 months (February 2015 to May 2015). We included all children between one month to 18 years in this study. Admission to PICU was based on the decision of the treating Paediatric Consultant. Assuming average mortality rate of $20-30 \%$, with an expected sensitivity of $85 \%$ and acceptable error of $5 \%$, the approximate sample size was calculated using the formula as 130 . A written informed consent was obtained from the parents before inclusion in the study.

Baseline characteristics of the study group including the clinical diagnosis were recorded. For statistical purposes children were categorised into two groups - group 1 (age < one year) and group 2 (age > one year). PIM2 score was calculated within one hour of admission. Ten variables of PIM2 score were recorded. The variables included were elective admission to PICU, recovery post procedure, cardiac bypass, highrisk diagnosis, low-risk diagnosis, no response of pupils to bright light (>3 $\mathrm{mm}$ and both fixed), mechanical ventilation (at any time during the first hour in PICU), systolic blood pressure $(\mathrm{mm} \mathrm{Hg})$, base excess $(\mathrm{mm} \mathrm{Hg})$ (arterial or capillary blood), and FiO2 *100/PaO2 (mm $\mathrm{Hg}$ ). Arterial blood gas analysis was done within one hour of admission and $\mathrm{PaO} 2$ and base excess were noted. Yes, or no response for these variables was entered as score 1 or 0 respectively. All the variables were entered into the system (www.sfar.org/scores2/ pim22.html) for calculation of PDR. PDR was calculated by the system using logistic regression equation.

PIM2 $=\left[0.01395^{*}(\mathrm{PaO} 2-120)\right]+\left[3.0791^{*}\right.$ Pupil sign $]$ $+\left[0.2888^{*}\left(\mathrm{FiO}{ }^{*} 100 / \mathrm{PaO} 2\right)\right]+\left[0.104^{*}\right.$ base $]+\left[1.3352^{*}\right.$ mechanical ventilation $]-\left[0.9282^{*}\right.$ elective admission $]-$ $\left[1.0244^{*}\right.$ recovery $]+\left[0.7507^{*}\right.$ cardiac bypass $]-\left[1.6829^{*}\right.$ high risk diagnosis] $-\left[1.5770^{*}\right.$ low risk diagnosis $]$ [4.8841].

PDR = exponential (PIM2)/1 + exponential (PIM2)

The length of PICU stay and total duration of hospital stay was recorded. Outcome was defined in terms of mortality and survival. The study population was categorised based on outcome as survivors and non survivors. All the data analyses were conducted using the SPSS version 21.0. The interval data were expressed as mean \pm standard deviation. Mortality risk was computed using Pearson's Chi Square test. Other factors at admission influencing mortality such as age, presence of shock, requirement for mechanical ventilation, low Glasgow coma scale (GCS < 8) and hypoalbuminemia were analysed along with the PDR to determine their association with mortality through univariate and multivariate regression analysis. The $p$ value was calculated with $95 \%$ confidence interval $(\mathrm{Cl})$. The statistical significance was considered with a $p$ value of $<0.05$.

\section{Results}

The study population included 130 consecutive children admitted to PICU during the study period. Table 1 shows the baseline characteristics of children included in the study including length of PICU and hospital stay along with the predicted death rate.

Children with PDR (Predicted Death Rate) less than $1 \%$ had a mortality rate of $2.4 \%$ (1 out of 42 ), when compared to $71.4 \%$ (10 out of 14 ) in children with PDR more than $5 \%$. The difference was statistically significant. ( $p$ value $<0.001)$. The mean PDR (\%) of the total study population was $22.4 \pm 10.60$. The mean PDR in survivors was $12.4 \pm 7.80$ while the PDR in non survivors was $44.2 \pm 12.62$. The difference was statistically significant ( $p$ value $<0.001$, using independent samples $t$ test). The observed death rate in the study was $37.7 \%(n=49)$ 
Table 2 describes the diagnostic categories of 130 patients and the mortality pattern. It was observed that neurological illnesses contributed highest to the mortality $(28.6 \%)$ followed by infectious diseases $(24.5 \%)$ and respiratory diseases $(16.3 \%)$.

Univariate binary and multivariate logistic regression analyses were performed to assess the association of mortality with other factors as depicted in table 3 and 4 respectively. The majority of factors except age less than one year were significantly associated with mortality in the unadjusted binary logistic regression analysis. In addition to PDR by PIM2 score, the association of hypoalbuminemia with mortality remained significant even after adjusting for age $(\mathrm{OR}=3.68 ; 95 \% \mathrm{Cl}, 1.76-7.74$; $\mathrm{p}<0.001)$.

Table 1: Baseline characteristics of the study group including length of stay and predicted death rate

\begin{tabular}{|c|c|c|c|}
\hline $\begin{array}{l}\text { Variable } \\
(n=130)\end{array}$ & $\begin{array}{l}\text { Survivors } \\
n=81(\%)\end{array}$ & $\begin{array}{c}\text { Non survivors } \\
n=49(\%)\end{array}$ & $p$ value \\
\hline \multicolumn{4}{|l|}{ Age } \\
\hline$<1$ year & $20(55.5)$ & $16(44.5)$ & \\
\hline$>1$ year & $61(64.9)$ & $33(35.1)$ & *0.32 \\
\hline \multicolumn{4}{|l|}{ Gender } \\
\hline Male & $56(69.1)$ & $25(30.9)$ & \\
\hline Female & $25(51.0)$ & $24(49.0)$ & ${ }^{*} 0.04$ \\
\hline Length of PICU stay (mean \pm SD days) & $4.6 \pm 3.06$ & $3.6 \pm 3.18$ & $\# 0.07$ \\
\hline Length of hospital stay (mean \pm SD days) & $11.8 \pm 8.72$ & $13.42 \pm 12.28$ & \#0.38 \\
\hline \multicolumn{4}{|l|}{ Predicted death rate } \\
\hline$<1 \%(n=42)$ & $41(97.6)$ & $1(2.4)$ & \\
\hline $1-5 \%(n=74)$ & $58(78.4)$ & $16(21.6)$ & \\
\hline$>5 \%(n=14)$ & $4(28.6)$ & $10(71.4)$ & ${ }^{*}<0.001$ \\
\hline Mean Predicted death rate $(\%)($ mean $\pm S D)$ & $12.4 \pm 7.80$ & $44.2 \pm 12.62$ & $\#<0.001$ \\
\hline
\end{tabular}

*Pearson's Chi square test, \# Independent Samples t test

Table 2: Diagnostic categories of the study population with mortality pattern

\begin{tabular}{lcc}
\hline $\begin{array}{l}\text { Diagnostic } \\
\text { Category }\end{array}$ & $\begin{array}{c}\text { Total number of } \\
\text { children } \mathbf{n = 1 3 0 ~ ( \% )}\end{array}$ & $\mathbf{n = 4 9 ( \% )}$ \\
\hline Neurological & $38(29.2)$ & $14(28.6)$ \\
\hline Infectious disease & $28(21.5)$ & $12(24.5)$ \\
\hline Respiratory & $21(16.5)$ & $8(16.3)$ \\
\hline Cardiovascular & $12(9.2)$ & $5(10.2)$ \\
\hline Oncology & $8(6.2)$ & $3(6.1)$ \\
\hline Toxicology & $8(6.2)$ & $2(4.1)$ \\
\hline Renal & $4(3.1)$ & $2(4.1)$ \\
\hline Gastrointestinal & $5(3.8)$ & $1(2.0)$ \\
\hline Postoperative & $3(2.3)$ & $1(2.0)$ \\
\hline Others & $3(2.3)$ & $1(2.0)$ \\
\hline
\end{tabular}

Table 3: Univariate logistic regression analysis of variables potentially associated with mortality

\begin{tabular}{lcc}
\hline \multirow{2}{*}{$\mathbf{n}=\mathbf{1 3 0}$} & \multicolumn{2}{c}{$\begin{array}{c}\text { Univariate binary logistic } \\
\text { regression }\end{array}$} \\
\cline { 2 - 3 } & ${ }^{*}$ OR $(\mathbf{9 5 \%} \mathrm{Cl})$ & p value \\
\hline Age $<1$ year & $1.04(0.86-1.06)$ & 0.32 \\
\hline Presence of shock & $1.12(1.08-1.20)$ & $<0.001$ \\
\hline GCS $<8$ & $1.24(1.18-1.36)$ & $<0.001$ \\
\hline Mechanical & $2.46(1.46-6.28)$ & $<0.001$ \\
ventilation & $4.28(1.68-10.12)$ & $<0.001$ \\
\hline Predicted death rate & $3.96(1.54-12.88)$ & $<0.001$ \\
\hline Hypoalbuminemia & & \\
\hline
\end{tabular}

* OR-Odd's ratio, $\mathrm{Cl}$ - Confidence interval
Table 4: Multivariate logistic regression analysis of variables potentially associated with mortality

\begin{tabular}{lcc}
\hline \multirow{2}{*}{$\mathbf{n}=130$} & \multicolumn{2}{c}{$\begin{array}{c}\text { Multivariate logistic } \\
\text { regression }\end{array}$} \\
\cline { 2 - 3 } & *AOR (95\% CI) & p value \\
\hline Age $<1$ year & $1.08(0.96-1.18)$ & 0.36 \\
\hline Presence of shock & $1.14(1.10-1.18)$ & $<0.001$ \\
\hline GCS < & $1.18(1.12-1.24)$ & $<0.001$ \\
\hline Need for mechanical & $3.11(1.63-5.92)$ & 0.001 \\
ventilation & $2.34(0.9-6.2)$ & $<0.001$ \\
\hline Predicted death rate & $3.68(1.76-7.74)$ & $<0.001$ \\
\hline Hypoalbuminemia &
\end{tabular}

* AOR- Adjusted Odd's ratio, Cl- Confidence interval

\section{Discussion}

PIM2 scoring system is one of the several scoring systems used to assess the severity of illness and to calculate the predicted death rate in children admitted to PICU. Studies have shown that PIM2 score compares well with the PRISM (Paediatric Risk of Mortality) score. ${ }^{4-8}$ In an Indian study done at New Delhi, the areas under the curve (95\% confidence intervals) for PRISM, PIM and PIM2 were 0.80 (0.74 to 0.86$), 0.82$ (0.76 to 0.88 ), 0.81 (0.75 to 0.87 ), respectively all above 0.8 confidence interval. ${ }^{7}$ In another study done at Women's and Children's Hospital, University of Adelaide, PIM2 
scoring system was found to be the most accurate amongst PIM, PRISM, and PRISM III. ${ }^{8}$

This prospective study was done to assess the performance of PIM2 score at a tertiary hospital in south India. Large number of referral cases account for higher mortality rates $(30 \%)$ in the hospital. The parameters in PIM2 score are easy to enter and calculation is simple. Another advantage of PIM2 score is that it is estimated within one hour of PICU admission unlike PRISM score which is estimated at 24 hours of admission. This has great implication as early identification of the severity of illness and mortality risk stratification is possible. ${ }^{9,10}$ Parents and care takers can be counselled at an early stage regarding the guarded prognosis of illness. PIM2 is also a good scoring system that holds good for intensive care units admitting trauma and post-operative cases.

Higher mortality rate was observed in children with neurological illnesses, which is similar to a study done by Gandhi $\mathrm{J}$ et al. ${ }^{10}$ This is attributed to higher number of children admitted with neurological illness. They also reported lesser duration of PICU stay in the mortality group. Though less duration of PICU stay was found in our study, it was not statistically significant. In the study by Gandhi $\mathrm{J}$ et al, PIM2 score discriminated between death and survival at a 99.8 cut-off, with area under receiver operating characteristic curve 0.843 with $95 \%$ confidence interval $(\mathrm{Cl})(0.765,0.903) .{ }^{10}$ We performed multiple logistic regression analysis to evaluate the effect of potential factors associated with mortality. Along with other factors, PDR calculated by PIM2 score remained as an independent predictor of mortality in children admitted to PICU. However, the mean predicted death rate of the study population by PIM2 scoring system was low compared with the observed mortality rate $(22.4 \%$ vs $37.7 \%)$. Thus PIM2 score under estimated the mortality in this study.

PIM2 score though discriminates well between risk groups, it poorly discriminates the diagnostic groups. Hence this system of scoring may not be suitable for different environments. ${ }^{5,10}$ Hence the limitation of this study is, it may not be applicable to all PICU settings. Prognosis and mortality risk largely depends on the disease pattern, the type of referrals and facilities available.

This is a single centric study and the results may not be applicable to the entire population. Multi-centric study would be warranted in the future to further validate our findings.

\section{Conclusion}

PIM2 score is a useful tool to assess the severity of illness and predict outcome in children admitted to intensive care. PIM2 scoring system discriminates well between survivors and non-survivors in the PICU setting of a tertiary care hospital though the predicted death rate may not correlate well with the observed mortality rate. Further studies are required to validate PIM2 scoring system and compare with other scoring systems in predicting outcome.

\section{References}

1. Becker RB, Zimmerman JE. ICU Scoring systems allow prediction of patient outcomes or comparison of ICU performance. Crit Care Clin. 1996;12:503-14. DOI: https://doi.org/10.1016/S0749-0704(05)70258-X

2. Marik PE, Varon J. Severity scoring and outcome assessment. Computerised predictive models and scoring systems. Crit Care Clin. 1999;15:633-46. DOI: https://DOI.org/10.1016/S0749-0704(05)70076-2

3. Shann F, Pearson G, Slater A, Wilkinson K. Paediatric index of mortality (PIM): a mortality prediction model for children in intensive care. Intensive Care Med. 1997;23(2):201-7. DOI: https://DOI.org/10.1007/ s001340050317

4. Gemke RJ, van Vught J. Scoring systems in paediatric intensive care: PRISM III versus PIM. Intensive Care Med.2002;28:204-7. DOI: https://DOI.org/10.1007/ s00134-001-1185-2

5. Hariharan S, Krishnamurthy K, Grannum D. Validation of Pediatric Index of Mortality-2 scoring system in a pediatric intensive care unit, Barbados. J Trop Pediatr. 2011;57:9-13. DOI: 10.1093/tropej/fmq031

6. Slater A, Shann F, Pearson G. Pediatric Index of Mortality (PIM) Study Group. PIM2: A revised version

of the Pediatric Index of Mortality. Intensive Care Med. 2003;29:278-85. DOI: https://DOI.org/10.1007/ s00134-002-1601-2

7. Thukral A, Lodha R, Irshad M, Arora NK. Performance of Paediatric Risk of Mortality (PRISM), Paediatric Index of Mortality (PIM), and PIM2 in a paediatric intensive care unit in a developing country. Paediatric Crit Care Med. 2006;7(4): 356-61. DOI: 10.1097/01. PCC.0000227105.20897.89

8. Slater A, Shann F. The suitability of the Paediatric Index of Mortality (PIM), PIM2, the Paediatric Risk of Mortality (PRISM), and PRISM III for monitoring the quality of paediatric intensive care in Australia and New Zealand. Pediatr Crit Care Med. 2004;5(5): 44754. DOI: 10.1097/01.PCC.0000138557.31831.65.

9. Wolfler A, Silvani P, Musicco M, Salvo I. Paediatric Index of Mortality 2 score in Italy: A multicenter, prospective, observational study. Intensive Care Med. 2007;33:1407-13. DOI: https://DOI.org/10.1007/ s00134-007-0694-z.

10. Gandhi J, Sangareddi S, Varadarajan P, Suresh S. Paediatric index of mortality 2 score as an outcome predictor in pediatric Intensive Care Unit in India. Indian J Crit Care Med. 2013;17(5):288-291. DOI: $10.4103 / 0972-5229.120320$. 